\title{
Development of a Sustainable Theoretical Framework for a Renewable Based Bathroom Unit
}

\author{
Toyosi K. Oye \\ School of Engineering and Built Environment, Edinburgh Napier University, UK \\ Naren Gupta \\ School of Engineering and Built Environment, Edinburgh Napier University, UK \\ Keng Goh \\ School of Engineering and Built Environment, Edinburgh Napier University, UK
}

Abdelfateh Kerrouche

School of Engineering and Built Environment, Edinburgh Napier University, UK

Tosin T. Oye

School of Engineering and Built Environment, Edinburgh Napier University, UK

Received: April 29, 2021 Accepted: May 14, $2021 \quad$ Published: May 23, 2021

doi:10.5296/emsd.v10i3.18537ＵRL: https://doi.org/10.5296/emsd.v10i3.18537

\begin{abstract}
One of the major issues facing the world in the 21 st century is climate change. However, sustainability has become a crucial concept to combat extreme consumption of environmental resources. The bathroom has been estimated to be the principal user of environmental resources in United Kingdom households. Therefore, the challenge that how a combined water and energy saving unit in the bathroom will contribute to the sustainability of the houses will remain unresolved. This study challenges and extends existing knowledge on sustainability related to the smart bathroom systems considering social, environmental, and economic principles to achieve a highly efficient water and energy consumption in the bathroom. This study gathers that a range of technological challenges are based on the
\end{abstract}


individual components and technologies in the bathroom and concludes that a holistic approach is required for an effective modelling in the bathroom. This allows the examination of energy and water flows in the complex systems, shaped by various social, economic and environmental forces. The method this study presented adopts conceptual and holistic modelling to design and implement a bathroom unit that is sustainable and smart. This study uncovers the contribution of renewable energy source and smart control technologies in the bathroom and the significant contribution it makes in levels of energy consumption and carbon emissions. These sustainable features are subsequently used to develop framework for sustainable for implementing and evaluation of sustainable bathroom system. This study has established a strong quantitative and qualitative links between three dimensions of sustainability.

Keywords: Bathroom, Sustainability, Water consumption, Energy consumption, Carbon emissions

\section{Introduction}

The effect of climate change is and will possibly keep on being a vital threat that experts need to manage globally in this century. The major effects of climate change are global warming, ice cap melting, sea-level rises, and precipitation changes. For instance, before 21 st century's over, standard UK summer temperature is probably going to increase by $3^{\circ} \mathrm{C}$ to $4^{\circ} \mathrm{C}$, normal summer precipitation in the UK might reduce by $11 \%$ to $27 \%$, while winter is a remarkable backwards and the UK ought to anticipate altogether wetter winters. Ocean levels are projected to rise, and extreme climatic conditions are probably going to turn out to be gradually normal (Oye et al., 2020a). Subsequently, it clearly shows that climate change can possibly have effect on environmental conditions and performance of water structure. Report from DEFRA in 2008 have highlighted that due to increasing population and the changes people have made in the way water is used in the UK, over $50 \%$ of UK water supply is now being delivered for domestic use. Therefore, resourceful management of water demand is of great importance in a domestic application. There is a general agreement that the UK will presumably encounter hotter conditions and lower summer precipitation in the nearest future (Jenkins et al. 2010; Parker 2014; Water UK 2016). Domestic water use is the key component of mains use of water. In the UK, the normal individual uses roughly 150 lit/day of drinking water for personal use (DEFRA, 2008). UK government has an objective of decreasing water use by $20 \%$ per individual by 2030 (ONNG, 2010). Defra, 2008 is committed to providing efficient measure to limit water consumption from 150 to 1301/person/day or probably 1201/person/day liable to technological improvement and invention.

Water and energy nexus are vital resources, fundamental for human life on planet earth. These resources have been key for social, economic, and environmental development. Within cities, households deserve particular attention because households are a major building block of cities. Several studies have demonstrated that the heating of water within households dominates energy use of the residential water cycle (Arpke and Hutzler 2006; Cheng 2002). In the UK, a great many households are already making savings and making a difference engaging in water saving behavior, cutting their bills and conserving resources. But since the 
average home uses nearly 360 litres of water every day, there is still astonishing potential to save water, energy, and utility bills through further change. According to Energy Saving Trust (2008), showers, lavatories, baths, and bathroom sinks consume more than two-thirds $(68 \%)$ of household water. On average, $16 \%$ of a household's energy bill relates to heating water for showers, baths, and hot water taps. This is on average about $£ 140$ a year. As a result, heated water contributes a lot to energy bills, bathroom uses the hottest water in the home, and so it is responsible for the most water-related carbon emissions. The energy used to heat water for devices and appliances emits an average of $875 \mathrm{~kg}$ of $\mathrm{CO} 2$ per household per year (Oye et al., 2020a).

Therefore, the challenge that how a combined water and energy saving unit in the bathroom will contribute to sustainability of the houses will remain unresolved. This study aims to challenge and extend existing knowledge on sustainability related to the smart bathroom systems considering social, environmental and economic dynamics.

The three bottom line principles of sustainability namely, economic, environment and social is significant in considering the sustainability of bathroom systems; however, the real issue confronting bathroom user with respect to the three bottom line principles of sustainability is whether human action is sustainable. For this study, the system framework is regarded as sustainable if:

1) the system considers the three pillars of sustainability namely, environment, economic and social. Whilst this study will focus on the three arms of sustainability, it will however concentrate majorly upon the strong sustainability aspect of the system and, or

2) the most efficient means for re-establishing the system to sustainability may necessitate change in the system. In other words, combining both the renewable and smart/ intelligent system as a unique system for the sustainability of the system which in turn improves the human adaptation of the wellbeing of occupants.

\section{Conceptual Issues of Sustainability in the Bathroom}

Currently, societies and humankind face sustainability challenges which primarily connects with the capacity to sustain ecosystems, humanity, and societies on the planet. In the future, these challenges are anticipated to turn out to be more substantial. Accomplishing sustainability in the bathroom is consequently one of the most vital objectives in any household since bathroom emit a lot of unsustainable resources to the environment.

The extreme energy and water consumption in a domestic bathroom bring about various hidden sustainability consequences and most especially their combined nexus impact. Some major effects results to an extreme energy and water consumption that cause challenges with the social, economic, and environmental sustainability, for example, degrading water surface because of contaminated surface overflow flushing into the water body, further water abstraction that causes degradation of the water body and high cost of maintenance with possible upgrade of water supply and treatment of waste-water mechanism. Although, for this study, the major purpose of saving water and energy is not only due to the decline in natural resources, water shortages, and rise in demand, but also due to the amount of carbon emission 
that could be saved in every liters of hot water utilized for bathroom activities.

According to (Families and Households, 2015) reports, the present pressure on the water supply corporation and water treatment coupled with the ongoing problem of water resources scarcity and depending on a newly manufactured systems will only bring out future imminent impact. Since UK population is roughly about 65 million with an average of 2.4 individual per house-hold and there are almost 27 million houses (old and new) coupled with a goal of building at least 2 million houses every year by the government, this will take the UK government over 100 years to implement a new water-energy saving system in all bathroom units in the UK if the innovation executed in all newly houses are being adopted for the existing house, consequently, retrofitting a domestic bathroom is a significant factor in any novel system for sustainability. To save water and energy for bathroom applications, the use of smart/intelligent control system is of great importance in any localized system. The smart controls system enables adaptation to the pattern of the end-user and further increases the efficiency of the system, this would be a substantial enhancement to an integrated system in any household dwellings to save both water and energy. Although in a domestic application, bathroom has the most potential to save water and energy, retrofitting a bathroom with an integrated water and energy saving technologies does not involve big makeovers in the bathroom building and will utmost result in being sustainable having maximum and timely influence. The adaptability of smart or intelligent systems in essential in retrofitting bathroom systems to be sustainable.

However, the concerns and issues personified through sustainability are comprehensive and many in bathroom applications. Though, the extensiveness of matters associated to sustainability proposes that a comprehensive and holistic tactic to sustainability is required. Sustainability actions are progressively becoming the businesses and governments agendas and operating strategies. The sustainability principles (environment, economic and social) are required to be associated if actions are to achieve the fundamental goals of sustainability in the bathroom.

\section{Sustainable Framework Assessment}

The sustainability evaluation process is critical for ensuring that sustainability is operational, as well as for tracking and assessing progress toward sustainability. However, measuring sustainability is difficult since no universally accepted sustainability strategy for a system exists. There are many reasons for this, including the difficulty of quantifying the main sustainability pillars (Hacatoglu et al., 2016). While ozone depleting substances and greenhouse gas emissions can be measured, determining their social and economic impacts is more difficult. Similarly, even though living standards are commonly measured in terms of "gross domestic product"; life quality can be an additional significant indicator of happiness, comfort, and human well-being. In this regard, determining sustainability can be contentious (Morse and Fraser 2005). However, as discussed below, several methods for measuring or assessing sustainability have been developed:

1) Some measurement approaches use metrics or sustainability standards, which are typically simple quantitative substitutions that systematically quantify environmental, 
social, and economic variables. Some sustainability indices are integrated, unifying the bottom-line values of social, environmental, and economic sustainability, while others are not, quantifying only a single sustainability fragment. As a result of its suitability and straightforward measuring proxies for the proposed scheme, this approach unifying the bottom-line concepts is analytically applied in this analysis.

2) Sustainability indices have been developed based on a composite or aggregate of various sustainability metrics. Because of its simplicity, a single-value sustainability quantity based on an aggregate index can be useful for communication and comprehension. Nonetheless, the determination of such metrics necessitates data collection, weighting, and normalisation. These stages usually result in the loss of useful knowledge which can be troublesome. The use of a single-value sustainability indicator can mask important aspects of sustainability's multidimensional nature, making it misleading. As a consequence of these established facts, this research avoided using such a quantification approach for the proposed system's framework sustainability evaluation.

3) Daly (1990) developed organisational principles for sustainable development through his research. While useful, these are limited to the quasi-sustainable use of non-renewable resources, and as a result, due to their limited use, this approach is not used in this analysis.

A limited number of sustainability evaluation methods, according to studies, simultaneously embody the three bottom-line principles of sustainability, namely economic, environmental, and social sustainability. Several approach evaluations, on the other hand, focus solely on one aspect or field of sustainability, such as the climate or economic sustainability. Several examples are considered to illustrate this, as seen below:

1) Biophysical approaches may be used to determine environmental quality by calculating environmental effects and resource use. However, they are often ineffective in resolving the economic and social aspects of sustainability.

2) Financial analysis may be used to measure environmental and social resources in order to determine sustainability. Nonetheless, due to our limited knowledge of ecosystems and the tools they provide, financial evaluations for non-market services and products are not well known, inappropriate appraisals, and problematic.

3) The index of environmental sustainability ranks countries based on a set of environmental metrics. Nonetheless, they are often unable to connect economic growth with environmental sustainability.

Numerous current approaches for assessing sustainability suffer from the lack of a framework approach, which considers the system as a whole and usually accounts for the relations among its subsystems. This is important because achieving a sustainable society is a systems issue in which the economic, social, and environmental systems are all interdependent. Integrated human-environmental systems have relations between various systems that essentially result in trade-offs; for example, cost-cutting can result in a procedure that is less efficient or emits more pollutants. Non-systems approach that focusses on single variables are often understood to be inadequate for holistically evaluating sustainability. Biophysical strategies, for example, place a strong emphasis on environmental sustainability while 


\section{Macrothink}

ignoring social and economic aspects, while approaches based on poor sustainability usually place a strong emphasis on economic factors while ignoring the biophysical sustainability domain. Obviously, a system's long-term viability must be measured using a systems framework approach. The life cycle analysis is typically a fragment of such a process, as it recognizes the system's energy and material inputs and outputs, or a process, and uses this knowledge to measure the effects of the system framework's economic, social, and environmental domains. In view of this, the sustainability principles, applied through a sustainable system, may be able to demonstrate success in lowering the level of energy consumption and carbon emissions of renewable-based bathrooms while improving smart control efficiency and improving the comfort of residents.

\section{Research Sustainable Theoretical Framework}

Figure 1 systematically presents and applies the three foundations of sustainability, namely, environment, economics, and social, resulting from the methodical structure outlined in this paper, and re-establishes the system to sustainability, which imposes system transformation. In other words, it integrates both a sustainable and a smart system into a single system for system sustainability, which increases human adaptation and user comfort.

Similarly, Figure 1 also sets out the research methodological sustainable theoretical framework proposed for this study to efficiently solve the sustainability problems in the bathroom. The three pillars of sustainability, namely, environment, social, and economic, are then added to this framework, describing the basis of the sustainable smart bathroom considered in this study. The proposed system's theoretical structure is extensively designed here by an adaptation strategy of the three bottom line principles of sustainability, as emphasized by Bell and Morse (1999); Moir and Carter (2012); Dreby and Lumb (2012) - in which the ecosystem is theoretically affected by both social and economic sustainability. As a result, going from top to bottom, this suggests a sustainable environment for a smart bathroom that is focused on sustainability. 


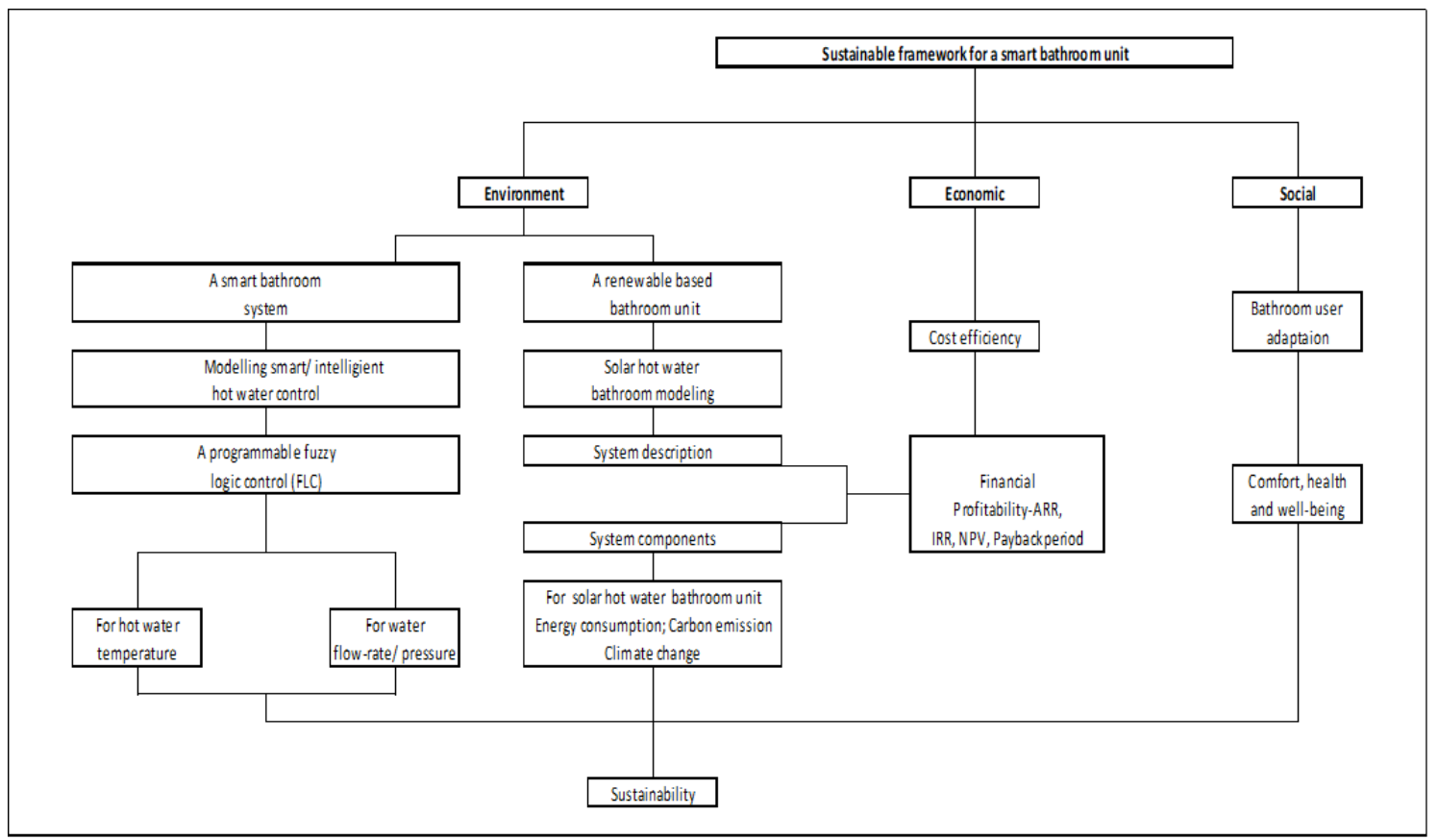

Figure 1. Research methodological framework

\section{From the Environmental Sustainability Standpoint}

There has been extensive work regarding how to improve the performance of solar water heating systems both experimentally and analytically as regards environmental performance in different academic field. Several studies from (Kulkarni et al., 2008, Hobbi and Siddiqui, 2009, Ayompe, 2015, Koke and Kuhr, 2018, Alessandro, 2020) have concentrated on the relationship between performance and design variables. Some examples of the latter are the storage tank size, the number of tanks, the solar collector area, the collector and heat exchanger flow rates, the hot water load profile, the hot water consumption, the auxiliary water heating device configurations, the cold make-up water replenishment profile, and the heat exchanger configuration. While these authors have majorly concentrated on a system components or parameters at a time for system design or optimization i.e., solar collector, boilers, storage tanks etc. Academic studies from Maria, 2015 and, Ayompe, 2015 have achieved a moderate system efficiency $26 \%$ and $31 \%$ respectively in terms of the energy savings and carbon emission savings they both search for. 


\subsection{The Modelling Processes}

Table 1. Modelling procedure

\begin{tabular}{|l|l|}
\hline The modelling process \\
\hline $\begin{array}{l}\text { System } \\
\text { description }\end{array}$ & $\begin{array}{l}\text { a system description of the problem situation and the system in which the } \\
\text { problem situation resides }\end{array}$ \\
\hline $\begin{array}{l}\text { Conceptual } \\
\text { model }\end{array}$ & $\begin{array}{l}\text { the conceptual model of non-software specific description of the computer } \\
\text { simulation model (that will be or has been developed), describing the } \\
\text { objectives, assumptions, input and output content of the model }\end{array}$ \\
\hline $\begin{array}{l}\text { Computer } \\
\text { model }\end{array}$ & A software specific design and software representation of conceptual model \\
\hline
\end{tabular}

\subsection{System Description}

The working principle for this study assumes the use of three solar flat plate collector connected in parallel, a backup hot water tank, pre-heating tank, solar heat exchanger, a gas water boiler to serve as auxiliary, circulators, pumps and mixing devices. The solar flat plate collectors are to be connected in parallel for them to be operating under the same conditions.

The solar radiation from the sun that is absorbed from the solar collector is transformed into heat energy. The collector heat transfer fluid (mixture of glycol and water) circulating in-between the solar heat exchanger and the solar collector transfer heat energy to the incoming potable water from the solar pre-heating storage tank and at that point the heat fluid returns to the solar collector for the next circulation and so on.

Each time the bathroom system requires hot water, the hot water stored in the storage tank is delivered to the outlet point i.e., the shower, tap, basin and the bathtub. The working principle is such that the incoming cold water from the main first enters the solar preheating tank with equivalent flowrate as the hot water delivered and consequently, the heated hot water in the pre-heated tank flow directly into the storage tank. If the pre-heated water temperature from the solar pre-heating storage tank is above the temperature set point from the water heater, then, the auxiliary water heat would not be activated and as a result, the hot water is delivered directly via the pre-heating tank to the hot water storage tank and then to the bathroom system once the system requires hot water. The auxiliary water heater is only switch on when the hot water temperature is lower that the temperature set point. If the water temperature from the solar pre-heating tank is above the circulator's deactivation set point, the circulation is shut down and no heated fluid is transported in to the solar-preheating tank. In scenario that the demand for hot is very high, or the solar energy is inadequate, the hot water temperature will be below the set point and the auxiliary water heater is activated. Generally, the hot water temperature from the hot water storage tank is higher than the bathroom hot water temperature demand, subsequently, the hot water is mixed with cold water in the mixing device component to obtain the user desired temperature. Also, since to the cold-water system makeup is pre-heated by the solar energy and the system components operations are collectively integrated, much energy savings is expected. 


\section{Macrothink

\subsection{Site Information and Data Collection}

London, United Kingdom, was chosen as the preferred location for this study since it boasts more solar resources than most other region in United Kingdom. The location used in this study is positioned at latitude $51.5^{\circ}$, longitude $-0.17^{\circ}$ and elevation of $36 \mathrm{~m}$. In this study, it is assumed that the home uses a boiler gas as auxiliary hot water heating system and position the storage tank and the pre-heating tank are relative to each other and at a short distance from the collector. This study uses a standard 400-litre pre-heating and backup tank and insulated piping.

\subsection{Simulation of Integrated Solar Bathroom Unit}

The simulation software Polysun (Polysun program, 2020) provides a comfortable and attractive graphical user interface, in which different integrated system model could be created. Even more it permits a comfortable and clear input of all system parameters and the analysis and design of energy systems. It runs with time steps $1 \mathrm{~h}$, thus simulation can be more stable and exact.

Therefore, the simplified representation of the proposed system is revealed below in Figure 2

In this system, the main components are solar collectors, connecting pipes, external heat exchangers, pre-heating tank, storage tank, pumps, and the auxiliary heating system. The solar collector is a kind of heat exchangers which is the key parts of the system. Solar collector absorbs the light falling on its surface, converts it into heat energy, and transfers this heat to the working fluid flow in solar collectors.

The solar collector is connected to the 4001 main water storage tank and a pre-heating tank. Thermal energy is transferred into the fluids travelling in the fluid flow pipes. The heat energy in the pipes is then transferred via the tanks. The heat allows the water in the main water storage to heat up to $60^{\circ} \mathrm{C}$. The pipes are then also connected to a $10 \mathrm{~kW}$ boiler.

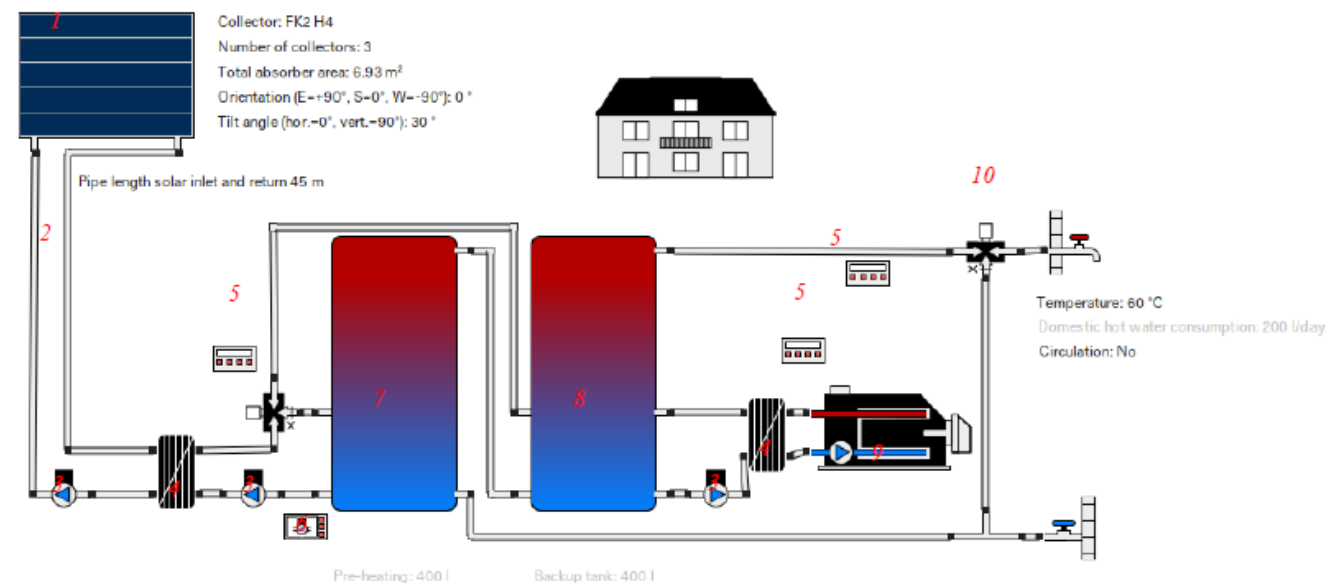

Figure 2. Simplified representation of the solar bathroom unit

1 = Collector, 2 = Connecting pipes, 3 = Solar pump, $4=$ Heat exchanger, $5=$ Auxiliary heating control, $6=$ Variable speed controller, $7=$ Pre-heating tank, $8=$ Backup tank, 9= Auxiliary boiler, $10=$ Mixing valve controller 


\section{Macrothink}

Environmental Management and Sustainable Development

ISSN 2164-7682 2021, Vol. 10, No. 3

\subsection{Result and Analysis}

The energy and environmental performance indices interested and investigated in this study for the bathroom modelling are the following:

- Solar Fraction

- Energy supply or yield

- Total energy consumption of the system

- Primary Energy Savings,

- System performance and efficiency

- Reduction of CO2 emissions

Table 2. Annual values for the system overview

\begin{tabular}{|l|l|}
\hline \multicolumn{2}{|l|}{ System overview (annual values) } \\
\hline Total fuel and/or electricity consumption of the system & $4,042 \mathrm{kWh}$ \\
\hline Total electricity consumption & $104 \mathrm{kWh}$ \\
\hline Total oil consumption & $4,529 \mathrm{kWh}$ \\
\hline Total energy consumption & $8,675 \mathrm{kWh}$ \\
\hline System performance & 0.95 \\
\hline Primary energy factor & 1.18 \\
\hline Comfort demand & Energy demand covered \\
\hline Overview of solar thermal energy (annual values) & \multicolumn{2}{|l|}{} \\
\hline Collector area & $7.5 \mathrm{~m}^{2}$ \\
\hline Solar fraction total & $65 \%$ \\
\hline Total annual field yield & $4,878 \mathrm{kWh}$ \\
\hline Collector field yield relating to gross area & $506.6 \mathrm{kWh} / \mathrm{m}^{2} / Y e a r$ \\
\hline Collector field yield relating to aperture area & $545.7 \mathrm{kWh} / \mathrm{m}^{2} /$ Year \\
\hline Max. fuel savings & 448.81 \\
\hline Max. energy savings & $4,487.9 \mathrm{kWh}$ \\
\hline Max. reduction in CO2 emissions & $1,349 \mathrm{~kg}$ \\
\hline
\end{tabular}

\subsection{Solar Fraction}

The annual results for the solar fraction showed that solar collectors produced thermal energy mostly depending on the percentage of the total solar fraction and depending on the collector field area. The higher the global irradiation level, the better efficiency, and higher thermal performance of collectors. If the temperature is increased, collector heat loss decreases.

\subsection{Energy Supply or Yield}

The result shows that, the total annual energy supplied to the bathroom system is $4,878 \mathrm{kWh}$. Energy supplied during the winter months is low as it can only provide $20 \%$ of the energy required, this means the auxiliary heating system works more during winter. Consequently, the auxiliary heating system is optimized to increase the efficiency of operation and to save 
significant amount of energy especially during the winter months. In the spring to summer season (April - Autumn), enough useful energy is supplied to the bathroom system with little auxiliary heating from the boiler for energy demand to be covered.

\subsection{Total Energy Consumption of the System}

The result shows that, the total annual energy consumed by the system is $8,675 \mathrm{kWh}$. This includes solar energy consumed, auxiliary energy consumed, and energy required to power other components for operation e.g., pumps, boiler, heat exchanger. The efficiency of the consumption is determined by the energy balance in the tank. The energy balance in the tanks is negative during the winter months due to energy lost to the environment. As a result, the system will consume more energy to make up for the lost energy.

\subsection{Primary Energy Savings}

This indicates the percentage of the primary energy saved in comparison to a conventional system where the same energy consumptions have to be covered and no renewable energy sources are used. After optimizing the system, the modeling result shows that however, solar thermal systems are still able to save between $56 \%$ of the energy that would have been required annually to heat up the hot water using conventional energy sources, such as gas or electric alone. Most of the savings occurred during the summer months while there was maximum $20 \%$ energy savings during the winter months.

\subsection{Reduction of CO2 Emissions}

After optimizing the system, the integrated solar bathroom system completely provided enough energy independently with overall annual solar CO2 savings of 1,398 kg. This signifies that the energy usage is efficient which enhances the performance of the overall system by making sure the system only uses the required hot water needed in the bathroom. This is one of the key benefits of system optimizing as opposed to individual component optimization.

\subsection{System Performance and Efficiency}

The system performance is a function of the solar fraction, energy supply and savings and heat lost. How efficient the system components interact together to generate effective outcome is summed up into single value. The higher the value the better the performance of the system. The result has demonstrated that there is generally better performance of the system during the summer months compared to the winter months. Although even during the winter months, the performance is still good. The average year performance of the system is 0.95 .

\subsection{Summary}

This section reckons that a range of technological challenges are based on the individual components and technologies in the bathroom and concludes that a holistic approach is required for an effective modelling in the bathroom. As a result, this study has designed and modelled a solar hot water bathroom from and holistic and integrated perspective which have 
saved a considerable 56 percent of energy use with high carbon emission. This study have demonstrated that integrated interactions of system components from holistic perspective is significant when considering the concept of solar hot water for use, extracting/collecting solar resource for both water and energy application in the bathroom although, using and optimizing a single technology would be of great advantage nevertheless, the efficiency of a single smart system is constrained to the level of its operation and other system components in the bathroom as evidenced in the work of Maria, 2015 and, Ayompe, 2015, this would not necessarily improve the overall sustainability of the bathroom unit. The concept of energy and water saving using integrated system appears unavoidable to enhance sustainability and focusing on future climate neutrality in bathroom and households while having an appropriate effect on the reduction of natural resources. The concept of the integrated system does not only collectively enhance the efficiency of water and energy nexus but in addition can lessen cost and size of the system components when compared to enhancing or improving each component in the bathroom, subsequently the payback time for an integrated system can be greatly reduce due to the significant incentive provided by the government for the property owner and home developers to adjust to an integrated system. This system will simply be smartly controlled to consider the user patterns and to enhance the utmost energy and water saving efficiency.

\section{From Social Sustainability Standpoint}

This study depicted social sustainability as a procedure for making sustainable and smart bathroom that encourage thermal and environmental comfort, by means of understanding what individuals need from the bathroom they use regularly. This ensures that the cohesion of bathroom users and the ability to work towards common goals (energy and water efficiency) are maintained while individual needs such as user thermal comfort should be met. Studies from (Partridge, 2005; Magee et al., 2012; Woodcraft et al., 2012) have mapped out social sustainability framework that help cultural and social life, social comforts, systems for resident commitment and space for individuals and galaxies to grow. The authors have also depicted as a social sustainability as informal and formal procedures, structures, systems, and connections effectively bolster the limit of present and future ages to generate live-able and healthy societies. While these state-of-art studies and works from (Akadiri et al., 2012, Krajacic et al. 2018 and Oye, 2018) have only discussed social sustainability associated with implementing sustainability in building sector, city and global. None of the studies on the state of art on social sustainability have discussed or mapped out how social sustainability is connected to hot water usage in the bathroom or in the household. This study tends to capitalize on this fact and designed smart and intelligent energy efficient controller for a bathroom system that is associated with hot water use, and can also influence environmental parameters and provide thermal comfort for its user. This study in addition have likewise proposed a smart hot water control technique that intelligently control hot water usage pattern which in turn also leads to a diminishing level of energy consumption and carbon emissions emanating from the use of hot water in the bathroom system. The design also offers an efficient and automatic control of water-flowrate and temperature in the bathroom that is tailored to the user hot water usage pattern that can also save energy in the bathroom system 


\section{Macrothink}

(Oye et al., 2020b).

The main idea behind the control system is to give a temperature set point to the controllers and by opening and closing the hot- and cold-water valves and should attain that temperature as quick as possible (Oye et al., 2020b). The core objective is to minimize the energy consumption for heating hot water without influencing the user's comfort. This can be achieved by maximizing the use of available energy coupled with fuzzy logic system.

\subsection{Simulation Model for FLC}

Simulink-MATLAB was used to simulate fuzzy logic control, and simulation results for the FLC model block diagram were obtained. The initial temperature for the cold and hot water circulation in the bathroom system, i.e., for the tub, taps, sinks, and toilet, was chosen at random between 0 and +60 degrees Celsius. The cold-water temperature and flowrate must trigger adjustment to the water going to the tap, tub, and sink using the valves to achieve optimum water temperature and flow quickly with just a few adjustments. The fuzzy logic takes charge of controlling water heating to fulfil and satisfy user requirements, the water temperature at any given time for hot water demand, and level of comfort by regulating the flow rate to maintain the least user desired temperature, i.e., the comfort level. The Mamdani fuzzy inference method is used in the bathroom hot water system; this system expects the output membership functions to be fuzzy sets. Following the fuzzification, each output has a collection of fuzzy values that must be de-fuzzified. Due to the computational simplicity required by the more general Mamdani method, this can be considered a pre-fuzzified fuzzy set, which improves the efficacy of the defuzzification method.

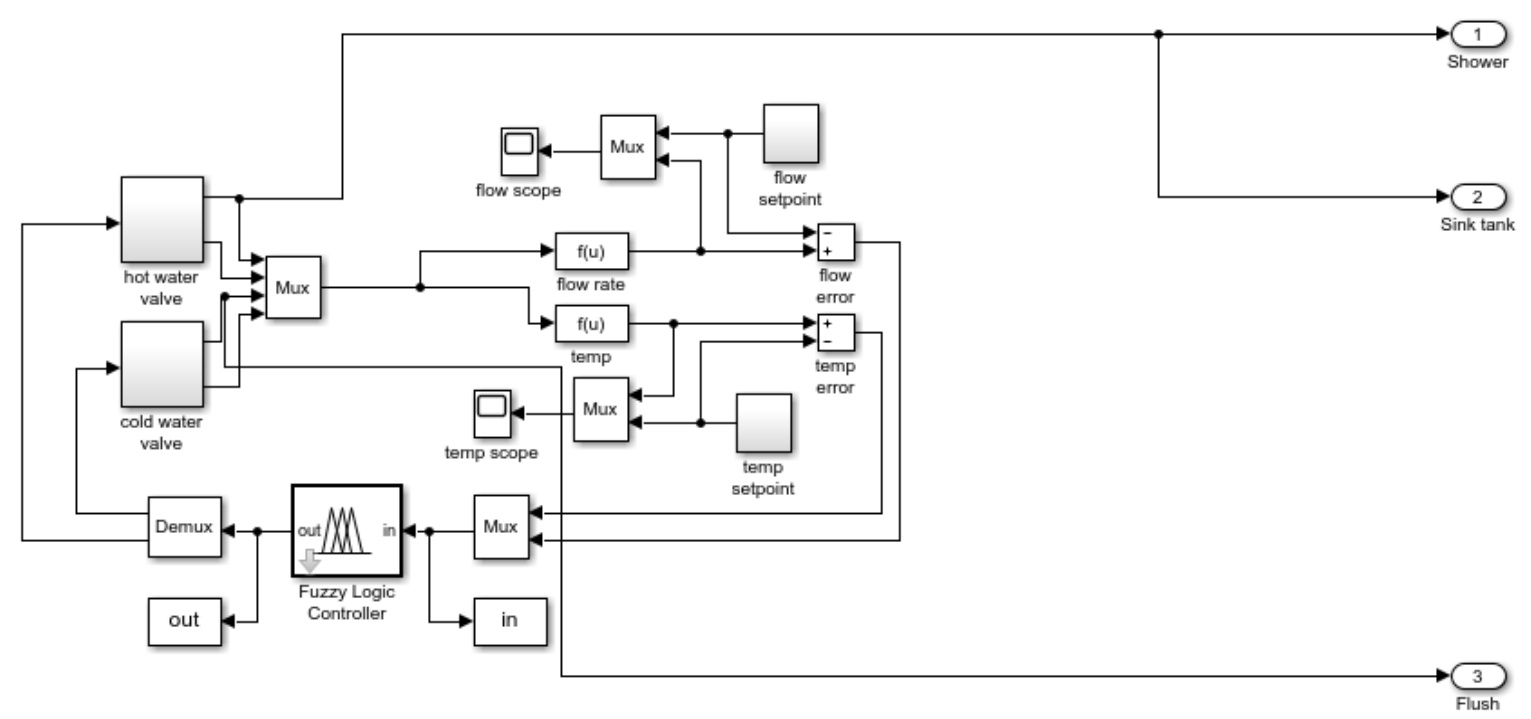

Figure 3. Simulink Model for hot water bathroom unit

Figure 3 shows a Simulink block diagram of the bathroom's hot water delivery method. Flow set point, time set point, cold water valve, and hot water valve are the four subsystems in this 


\section{Macrothink}

model. The signal generator that produces the flow rate variance is part of the flow set point subsystem. The signal generator provides a square wave input signal with an amplitude of 0.2 and a normal frequency of $0.3 \mathrm{rad} / \mathrm{sec}$. The signal generator that produces temperature fluctuations is part of the temperature set point subsystem. The input signal has an amplitude of four and a normal frequency of $2143 \mathrm{rad} / \mathrm{sec}$. The fuzzy logic controller sends signals to the cold-water valve system and the hot-water valve system (FLC) to initiate the valves opening. The bathroom consumer adjusts hot and cold-water valves to regulate the flow rate and temperature of a shower in this system. Since the fuzzy system has two inputs, the model uses a Mux block to concatenate the signals. The Mux block's output is related to the Fuzzy Logic Controller block's input. Similarly, a Demux block connected to the controller is used to receive the two output signals.

The bathroom system's fuzzy controller alternates between two input controllers (temperature and flow controllers) and generates two necessary outputs (cold and hot). The valve opening will be regulated by this performance. Figure 4 depicts the fuzzy inference scheme. In the fuzzy logic controller, there are nine rules described. The following are the laws that were used:

\section{Rule Editor: shower}

File Edit View Options

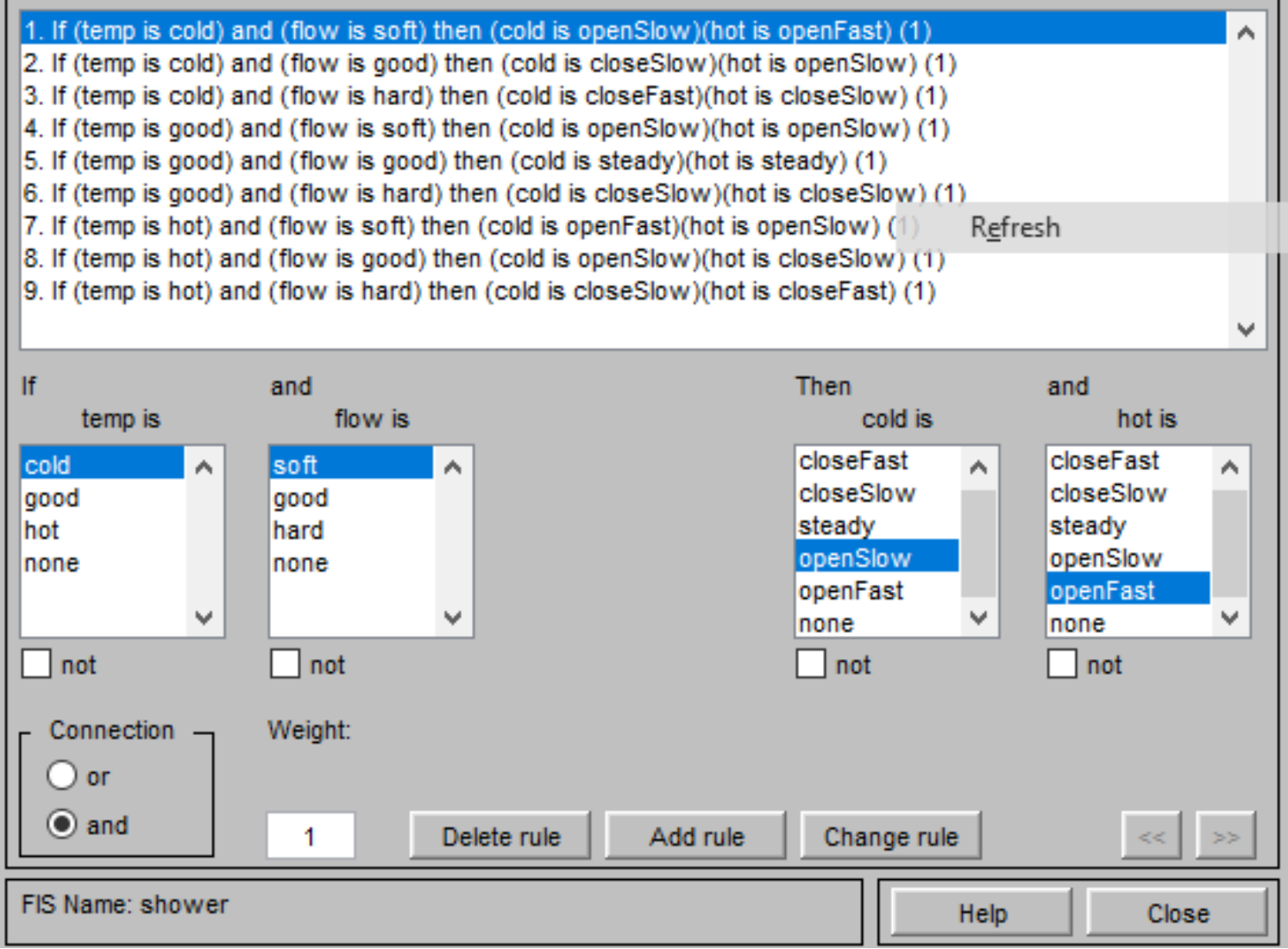

Figure 4. Rule editor for valve control 


\section{Macrothink}

The rule editor was built with a graphical rule interface and is based on input and output variables specified in the FIS editor, allowing for the automatic generation of rule statements.

\subsection{Results and Discussion}

The membership functions and collection of fuzzy rules mentioned in the preceding in Figure 4 were used in simulations to determine the efficacy of using fuzzy logic to minimize energy and potable water consumption in the bathroom application. The fuzzy logic toolbox in MATLAB was used to simulate two input and one output device. Each of the two inputs has three fuzzy levels, while the output parameter has nine levels. A rule base of nine rules will be activated to ensure that the user's target temperature and flowrate are met. The crisp defuzzied values for the corresponding crisp inputs are obtained using the rule viewer. It depicts the mechanism of fuzzification and defuzzification. The result for the controller on simulation with the specified parameters is shown in the FLC and Simulink graphs. At the user-specified temperature and flowrate, the controller stabilizes shows transient. In comparison to all other controls, the FL control has little overshoot, steady state error, and stabilizes easily to the exact user desired flow rate and temperature. The rule editor controls the phase reaction of the flow rate and the temperature controls of the bathroom system. The figures show that the system's phase response is very effective, with minimal overshoot, a fast rise time, and no steady state error. The advantage of using FLC for this study is that it supports the water heater by offering much better performance regardless of the manufacturer's rating and, as a result, decreases energy consumption by a more precise measurement of the power required to achieve and maintain the target temperature rather than relying on binary principles (hot or cold). The FLC also calculates or forecasts the amount of energy required to reach the desired temperature, causing the energy demand to decrease proportionally until the desired temperature is reached. The water heater is not supposed to undershoot or overshoot as seen in Figure 5 and Figure 6 while making +/- modifications against the temperature aimed along what product manufacturers call the "heat rise curve". Since the FL controllers generate finer graduations between discrete temperature values and given that the heater is now more precise because of using fuzzy logic control, this means, it uses less energy. 


\section{Macrothink Institute $^{\text {TM }}$}

Environmental Management and Sustainable Development ISSN 2164-7682 2021, Vol. 10, No. 3

4 xre sope

Fie Tert Ker 5risten Ho

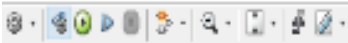

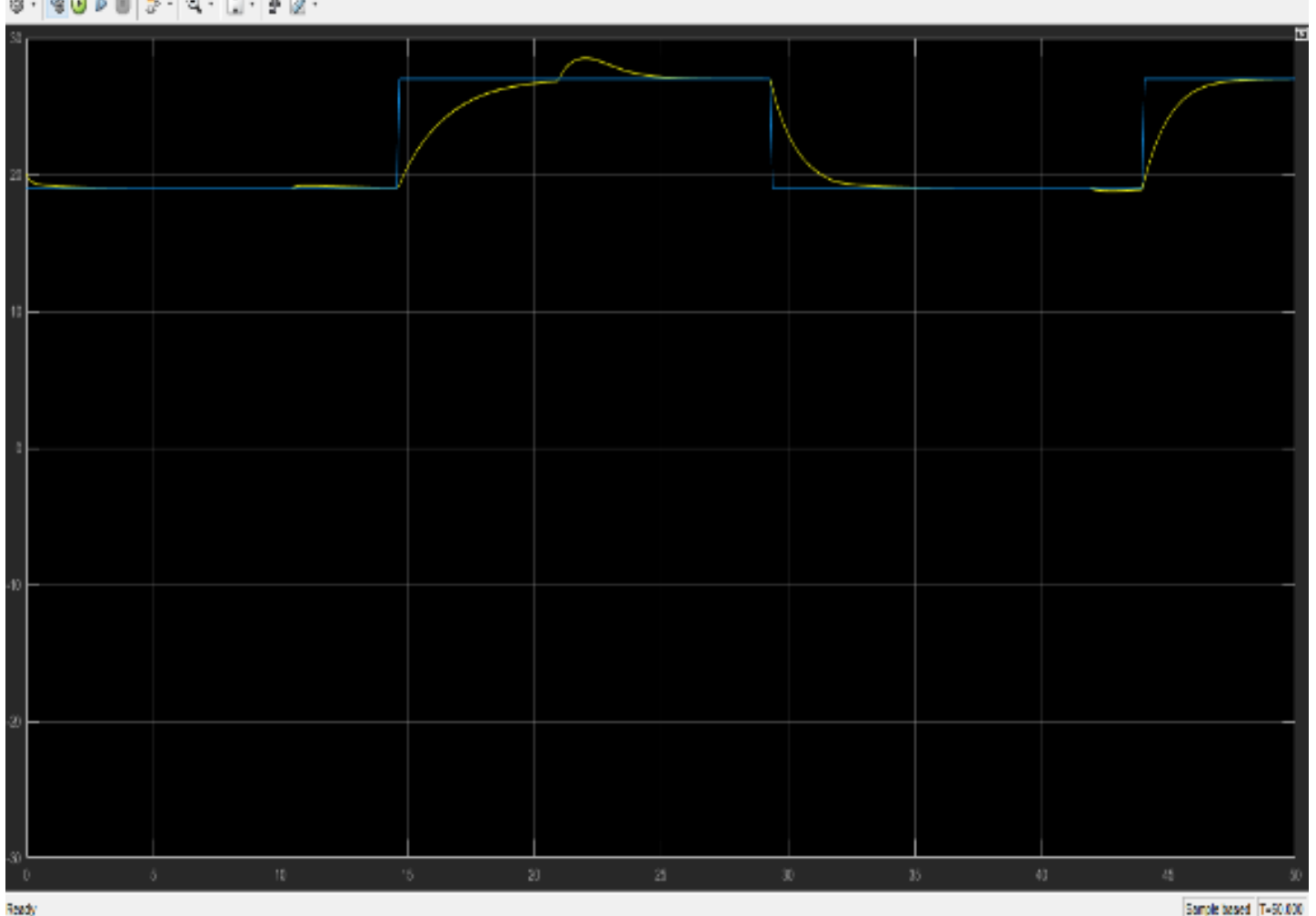

Figure 5. Step responses for temperature simulation

Fie Tosk lien Sim.lotisn Hep

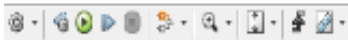

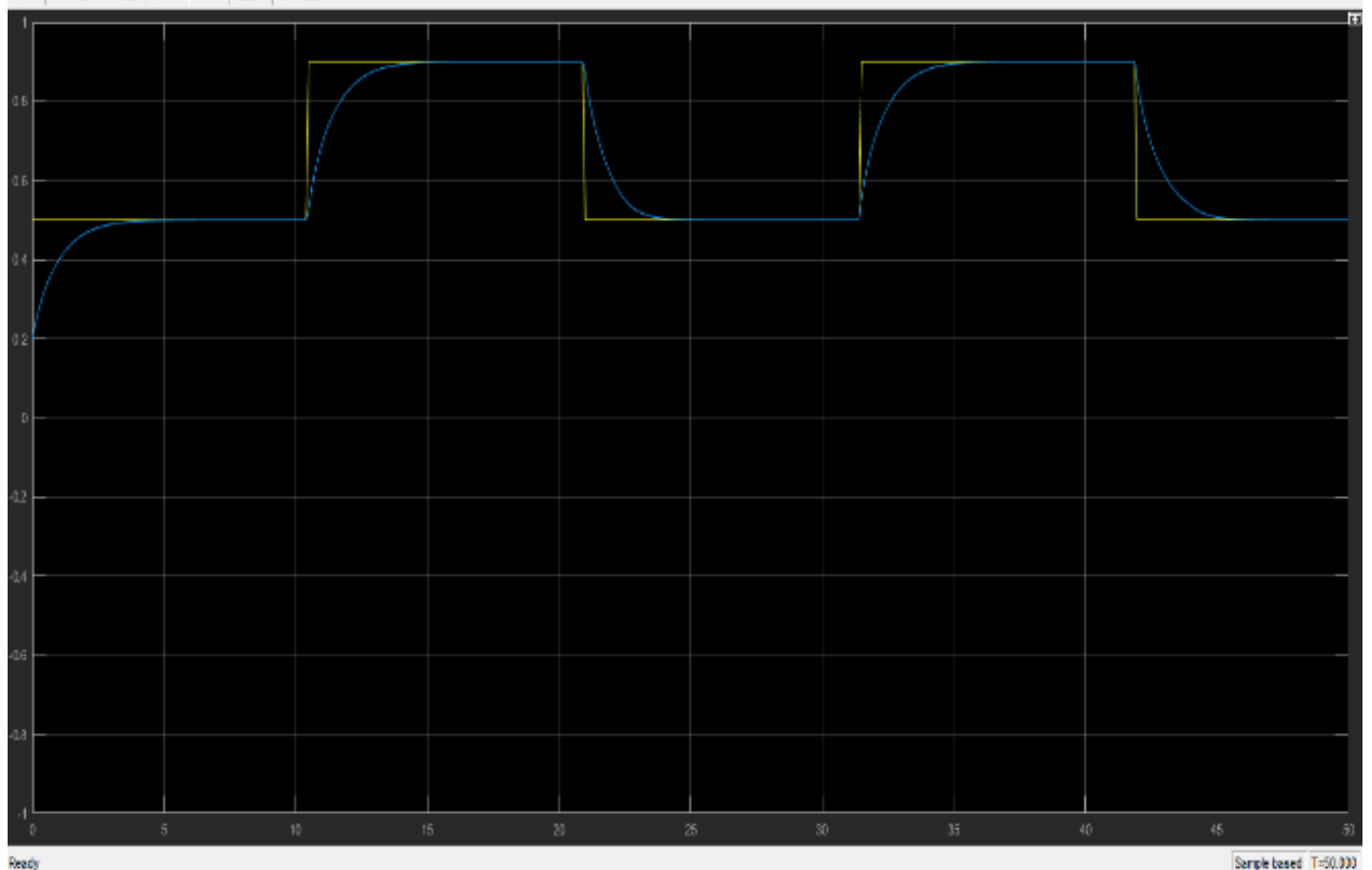

Figure 6. Step responses for flowrate simulation 


\subsection{Thermal Comfort}

If the bathroom saves energy and performs very well and does not positively influence the user's comfort in the bathroom and improve efficiency, then the bathroom is not sustainable. Thermal comfort is key to user satisfaction and productivity and maintaining good thermal comfort is one of the key objectives in the development of the sustainable framework for bathroom. This study uncovered that the use of traditional flow controls in the bathroom does not provide thermal comfort and could cause burns on the skin. In the attempt to increase the hot water flowrate to the user preferred setpoint, the water volume and temperature also increases which could rise to unsafe degree and cause harm. The environmental parameter (water temperature, and flowrate) which constitute the thermal environment in the bathroom have been controlled in such a way that it will improve the thermal comfort greatly as well as improving the energy efficiency.

\section{From Economic Standpoint}

This occurs when development in the bathroom that support economic growth is financially feasible and does not hinder the environmental and social sustainability. Nevertheless, economic sustainability is inseparably connected to both social and environmental sustainability. Studies from Meadows et al., (2004), Gilding (2011), Thomson (2013), Jones et al., (2013) have discussed and that suggested that economies are unlikely to be sustainable if society keeps-on relying upon marvels that hitherto drove development and if natural assets are utilized past the cut-off points and agreed that the use of cost saving technology, reduced running cost with minimum maintenance are paramount. As a result, this study has proposed system components that are cost efficient with good return on investment with minimum payback time. This study has also modelled a solar hot water bathroom using that saves significant energy that will in turn reduce cost in use for the bathroom system.

\subsection{Profitability Analysis}

Apart from long-term and short-term creditors, management and owners are also interested in the solar bathroom's sustainability, which can be maintained by profitability analysis. The profitability evaluation is divided into two groups. Those that show profitability in relation to investment and those that show profitability in relation to sales. Both tests are used together to determine the system's overall effectiveness. This research is conducted from the perspective of the system's management/owner to assess the proposed system's viability. The proposed system's management/owner is very eager to assess the solar bathroom's operational quality. As a result, the owners leverage their assets in the hopes of generating fair returns. The operating efficiency of the solar bathroom unit, as well as its ability to guarantee satisfactory yields, are ultimately dependent on the profits produced by the system.

According to a research published by Renewable Energy Hub in 2021, the estimated annual energy of solar system components for a bathroom system is $3,926 \mathrm{kWh}$. The average cost of a solar bathroom unit in 2021, according to Renewable Energy Hub, is $£ 4800$, which covers all system components and construction costs, with an annual revenue of $£ 8500$. However according to research, the cost of device implementation is estimated based on the following 
factors:

1) the costs of the equipment, which are mostly determined by its category

2) the costs are dependent on the precise location and type of building involved.

3) It is also dependent on the level of pay in engineering domains in the environment.

However, the average installation costs of solar bathroom units are used. To ensure precision and continuity in the evaluation of financial profitability, all values in this study are measured in pounds sterling. As a result, the listed maintenance costs are made up of system adjustments and periodic inspections. According to the manufacturer, the system components have a lifetime of twenty years, and the estimated annual maintenance costs for the system are $£ 100$. The photovoltaic system's annual feed-in tariff and export tariff are 14.90p per unit and $4.64 \mathrm{p}$ per unit, respectively, with a twenty-year tariff lifetime guaranteed.

The profitability of the proposed scheme was calculated in this analysis using the accounting rate of return, payback period, net present value, and internal rate of return, as discussed and analyzed in the subsections below.

The accounting rate of return formula is defined in the equation below in this study:

$$
A R R=\frac{\text { Average Annual Profit }}{\text { Initial Investment }} \quad X 100
$$

Average Annual Profit $=$ Revenue - Annual Maintenance Cost

Average Annual Profit $=8500.00-100.00=8400.00$

$$
A R R_{20}=\frac{8400.00}{4800.00} \quad X 100=175 \%
$$

The initial investment in the solar bathroom unit is $£ 4800.00$, with annual maintenance costs of $£ 100.00$ and maintenance costs of $£ 2000.00$ after twenty years of service. In addition, the solar bathroom unit investment, which covers maintenance costs over the course of twenty years, is $£ 6800.00$. This is the amount of the original expenditure and the expense of maintaining it for a period of twenty years. The system's proposed revenue is $£ 8500.00$. (business income from its normal business activities). The estimated annual profit is $£ 8400.00$, which is calculated by subtracting the annual system operating expense from the revenue. The accounting rate of return is calculated by dividing the system initial investment by the estimated annual benefit. The accounting rate of return (ARR) is 175 percent as a result.

In this study, the formula for the net present value is expressed in the Equation (3) below:

$$
N P V=\Sigma \frac{C_{i}}{(1+r)^{n}}-\text { Initial Investment }
$$

Where $C_{i}$ is the cash flow generated per year; $r$ is the rate of inflation and $n$ is the number of years. For higher net present values are advantageous and the rule for precise decision is as follows: 
- $\quad N P V>0$, accept project

- $N P V \leq 0$, reject project

Inflation, on the other hand, could increase the future revenue of a solar bathroom unit. The viability of substitute investments decreases the potential revenue value, and bank deposit interest can be useful in this situation. The proposed annual inflation rate used in this analysis is $4 \%(4 \%)$ with a $5 \%$ discount rate (5 percent). Furthermore, the average yearly power of the solar system must be multiplied by the feed-in-tariff and the export tariff, respectively, to obtain the initial income produced, and then added together. As a result, Equation 4 can be used to determine this:

$$
\text { Annual Income }=(0.149 \times 3926)+(0.0464 \times 3926)=£ 767.14
$$

As a result, Table 3 revealed the operating profit, generated income and cash flows for the next twenty years of the system

Table 3. The system annual income, operating profit and cash flows

\begin{tabular}{|l|l|l|l|l|l|}
\hline Annual & Initial Investment & Income & Annual Maintenance Cost & Operating Profit & Cash Flow \\
\hline Year 0 & $-£ 4800$ & - & - & - & - \\
\hline Year 1 & - & 767.14 & 100.00 & 667.14 & 667.14 \\
\hline Year 2 & - & 797.84 & 100.00 & 697.84 & 697.83 \\
\hline Year 3 & - & 829.75 & 100.00 & 729.75 & 729.73 \\
\hline Year 4 & - & 862.94 & 100.00 & 762.96 & 762.93 \\
\hline Year 5 & - & 897.46 & 100.00 & 797.46 & 797.45 \\
\hline Year 6 & - & 933.36 & 100.00 & 833.36 & 833.34 \\
\hline Year 7 & - & 970.69 & 100.00 & 870.69 & 870.68 \\
\hline Year 8 & - & 1009.52 & 100.00 & 909.52 & 909.50 \\
\hline Year 9 & - & 1049.90 & 100.00 & 949.90 & 949.88 \\
\hline Year 10 & - & 1091.90 & 100.00 & 991.90 & 991.88 \\
\hline Year 11 & - & 1135.58 & 100.00 & 1035.58 & 1035.55 \\
\hline Year 12 & - & 1181.00 & 100.00 & 1081.00 & 1080.98 \\
\hline Year 13 & - & 1228.24 & 100.00 & 1028.24 & 1128.22 \\
\hline Year 14 & - & 1273.37 & 100.00 & 1173.37 & 1177.34 \\
\hline Year 15 & - & 1324.30 & 100.00 & 1324.30 & 1228.44 \\
\hline Year 16 & - & 1377.27 & 100.00 & 1277.27 & 1281.58 \\
\hline Year 17 & - & 1432.36 & 100.00 & 1332.36 & 1336.84 \\
\hline Year 18 & - & 1489.65 & 100.00 & 1389.65 & 1394.31 \\
\hline Year 19 & - & 1549.24 & 100.00 & 1449.24 & 1454.08 \\
\hline Year 20 & - & 1611.21 & 100.00 & 1511.21 & 1516.25 \\
\hline
\end{tabular}

Likewise, the NPV in equation (3) can further be expressed as:

$$
\frac{C_{i}}{(1.05)^{1}}+\frac{1.04 C_{i}}{(1.05)^{2}}+\frac{1.04 C_{2}}{(1.05)^{3}}+\frac{1.04 C_{3}}{(1.05)^{4}}+\frac{1.04 C_{4}}{(1.05)^{5}}+\cdots \frac{1.04 C_{n}}{(1.05)^{n}}
$$

In order to obtain the NPV of the proposed system, it is essential to substitute the yearly cash 


\section{Macrothink}

flow presented in Table 3 into Equation (5). Therefore, the twenty-year net present value at discount of rate $5 \%(0.05)$ can be expressed as follows:

$$
\begin{aligned}
& N P V=\frac{667.14}{1.05^{1}}+\frac{697.83}{1.05^{2}}+\frac{729.73}{1.05^{3}}+\frac{762.93}{1.05^{4}}+\frac{797.45}{1.05^{5}}+\frac{833.34}{1.05^{6}}+\frac{870.68}{1.05^{7}}+\frac{909.50}{1.05^{8}} \\
&+\frac{949.88}{1.05^{9}}+\frac{991.88}{1.05^{10}}+\frac{1035.55}{1.05^{11}}+\frac{1080.98}{1.05^{12}}+\frac{1128.22}{1.05^{13}}+\frac{1177.34}{1.05^{14}} \\
&+\frac{1228.44}{1.05^{15}}+\frac{1281.58}{1.05^{16}}+\frac{1336.84}{1.05^{17}}+\frac{1394.31}{1.05^{18}}+\frac{1454.08}{1.05^{19}}+\frac{1516.25}{1.05^{20}} \\
&- \text { Initial Investment } \\
& N P V=633.37+632.95+630.37+627.66+624.82+621.85+618.78+615.59 \\
&+612.30+608.93+605.46+601.93+598.32+594.64+590.90 \\
&+587.11+583.26+579.36+575.43+571.46-4800 \\
& N P V=12114.29-4800=£ 7314.29
\end{aligned}
$$

It can be observed that the proposed project yielded a positive value $N P V>0$, which suggests the project is worth undertaking.

Since the proposed project possesses uneven cash flows, the formula employed for the payback period can be expressed in equation (6) as:

$$
\text { Payback Period }=\frac{\text { Initial Investment }}{\text { Periodic Cash Flow }}
$$

As a result of an uneven cash flow and to determine how much time to recover the original investment, the payback period can further be expressed as:

$$
\text { Payback }=\text { Years before full recovery }+\frac{\text { Unrecovered cost at start of the year }}{\text { Cash flow during the year }}
$$

Furthermore, year 6 (six) is the year before the initial investment is fully recovered; however, to calculate the unrecovered cost at start of the year, the initial investment must be subtracted from the addition of the cash flows by the end of the $6^{\text {th }}$ year. Furthermore, the cash flow during the year is the flow of cash when the project has fully recovered from its initial investment.

$$
\text { Unrecovered cost at start of the year = Initial Investment }- \text { Cash flows by the end of year } 6
$$

Subsequently, the payback period is expressed and calculated as follows:

$$
\begin{gathered}
\text { Payback }=6+\frac{311.58}{870.68} \\
\text { Payback period }=6.4 \text { years }
\end{gathered}
$$

In this study, the estimated payback period is 6.4 years, and this typically demonstrates that the system will begin to make profit after 6.4 years of operation.

The accounting rate of return, net present value, payback period and the internal rate of return has been evaluated and the analysis portrayed that the project is worth undertaking. The 


\section{Macrothink}

Environmental Management and Sustainable Development

ISSN 2164-7682

2021, Vol. 10, No. 3

economic assessment of the solar-based systems demonstrates how significant savings can be achieved through utilizing a sustainable and renewable means of technology, the solar bathroom unit technology. Moreover, the financial profitability factors evaluated appears to possess several advantages and drawbacks; this has been taken into consideration in the assessment of the system. Therefore, the solar bathroom system demonstrates the ability to reduce the level of energy consumption, carbon emissions and saves investment costs; however, it also analytically demonstrates to meet the sustainable agenda in this study, which is the economic sustainability of the renewable bathroom unit.

\section{Development of Sustainable Framework for Bathroom Unit}

In the feasibility study for the development of sustainable framework for smart solar hot water energy bathroom unit for this research work, it was necessary to construct a conceptual framework to enable this research to map out the state-of-art in terms on how to achieve sustainability balance from three standpoints, namely: the environmental, economic, and social sustainability.

The environmental sustainability requires economic sustainability, and social sustainability relies on environmental sustainability. On the other hand, the three areas of sustainability can be treated with equality as proposed by this study. The promotion of sustainable practices is to typically pursue a balance between environment, economic and social performance in project applications. The results sections in this study shows that, the connection amongst sustainability, renewable energy and smart control for bathroom becomes clear to reduce the level of energy consumption and rates of carbon emissions while the associated link to social sustainability tackles thermal comfort of bathroom user; bathroom system is of strong environmental significance and subsequently has high economic and social influences. Therefore, based on standpoints discussed in the sections above, the principles of sustainability namely, environment, economic and social aimed for renewable smart bathroom are theoretically addressed for the development of a suitable sustainable framework in the following subsections. 


\subsection{The Proposed Sustainable Framework}

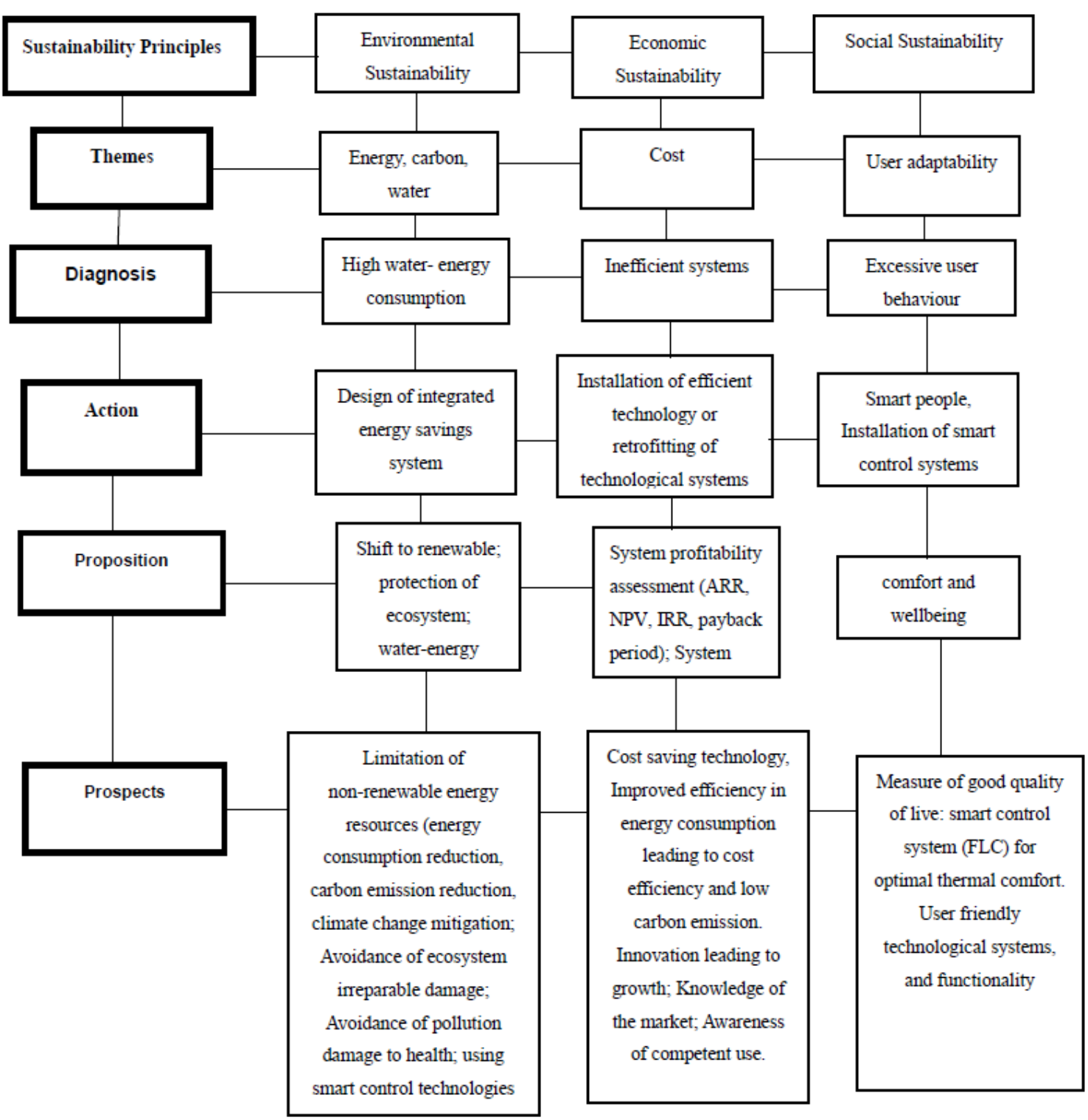

Figure 7. Proposed framework using sustainability principles and indicators

The framework begins by taking holistic approach to the problem of achieving sustainable and smart bathroom, identifies specific challenges that the bathroom unit must overcome, and finally focuses on the possible opportunities to overcome these identified challenges. The sustainable framework serves to affirm and present the key models as part of the sustainability approach by systematically contributing sustainable solution in a bathroom context. The first column highpoints the triptych in terms of the environmental, economic, and social sustainability. This in turn leads to the key sustainable themes linked to the energy, carbon, water, cost, and user adaptability central to smart sustainability principles. Under this lies a further level of analysis focusing on the diagnosis, action and proposition of designers and engineers in securing the sustainability of the bathroom part of an inclusive growth 
strategy in a wider context. The literature emphasized that significant variation currently exists in what scholars' target in terms of sustainability approaches to improve the performance in the bathroom from Environmental (emissions reduction), Economic (Cost efficiency) and Social (user inclusion) standpoints. While it has been a generalized approach for researchers to favor an aspect of sustainability principle over the others to measure the overall sustainability due to lack of a holistic sustainable framework as this makes it difficult to ascertain if truly bathrooms are sustainable or not. This will lead to suspicion and distrust in claims. The holistic sustainable framework developed in this study for achieving bathroom sustainability will work well in the general sense that it will promotes actions towards low energy use, a high degree of renewables and local energy generation and that the bathroom can function as a catalyst for the households and several commercial sectors to reduce emissions. This will help to make claims and assertions much more meaningful and comparable, bring greater credibility to the concept of sustainability approaches and thereby increase the opportunity for the approaches to become mainstreamed into a wider context. Without this, the more ambitious target of carbon neutral might never be possible. The road mapping actions can serve as driving forces for innovation as well.

\section{Conclusion}

The aim of this study is to challenge and extend existing knowledge on sustainability related to the smart bathroom systems considering social, environmental and economic dynamics. In line with these, this study has developed a sustainable theoretical framework for smart bathroom which is focused upon conceptual modelling approach that are suitable and fundamentally connected to the scope of this study. The advancement of overall sustainability to pursue balance among environmental, economic and social sustainability for a bathroom is not negotiable, the connection between bathroom and sustainability is strong; cost of designing and construction is of high economic importance and has strong social and environmental effects. As a result of the three bottom line principles of sustainability adapted in this study, the results demonstrate accomplishment in the reduction of energy consumption and carbon emissions with exceptional control performance and user comfort improvement.

\section{Recommendations for Future Studies}

1. Further research can subsequently perform the experimental test of the system since the conceptual modelling and the theoretical working analysis of the solar based bathroom unit are unfolded in this study.

2. Future studies can perform an experimental test of the developed fuzzy logic control to evaluate the response of the system to flow and temperature change.

3. Future studies can consider other renewable energy technologies such as wind energy, hydropower, geothermal energy, etc., and subsequently integrate such renewable energy into the developed sustainable framework as an alternative source of energy. Thereby, comparing the outcome of solar energy to other renewable energy sources and further extending the developed sustainable framework. This would provide an even better understanding of carbon emissions and energy performance of sustainable-based bathroom associated with the influence of the developed sustainable-based theoretical framework. 


\section{References}

Akadiri, P. O., Chinyio, E. A., \& Olomolaiye, P. O. (2012). Design of A Sustainable Building: A Conceptual Framework for Implementing Sustainability in the Building Sector. Buildings, 2, 126-152. https://doi.org/10.3390/buildings2020126

Alessandro, F. (2020). Methods for the Sustainable Design of Solar Energy Systems for Industrial Process Heat. Sustainability, 12, 5127. https://doi.org/10.3390/su12125127

Arpke, A., \& Hutzler, N. (2006). Domestic Water Use in the United States. A Life-Cycle Approach. Journal of Industrial Ecology, 10(1-2), 169-183.

https://doi.org/10.1162/108819806775545312

Ayompe, L. (2015). Performance and Policy Evaluation of Solar Energy Technologies for Domestic Application in Ireland. Doctoral Thesis. Technological University Dublin.

Bell, S., \& Morse, S. (1999). Sustainability Indicators: Measuring the Immensurable. London: Earth scan.

Cheng, C.-L. (2002). Study of the Inter-Relationship between Water Use and Energy Conservation for a Building. Energy and Buildings, 34, 261-266.

https://doi.org/10.1016/S0378-7788(01)00097-4

Daly, H. E. (1990). Toward some operational principles of sustainable development. Ecological Economics, 2, 1-6. https://doi.org/10.1016/0921-8009(90)90010-R

DEFRA. (2008). Future Water: The Government's water strategy for England. [Online] Available: https://www.waterwise.org.uk/knowledge-base/future-water-the-governments-wat er-strategy-for-england-2008/

Dreby, E., \& Lumb, J. (2012). Beyond the Growth Dilemma: Toward an Ecologically Integrated Economy. Quaker Institute for the Future, Producciones de la Hamaca, Belize.

Energy Hub. (2021). The renewable energy United Kingdom. [Online] Available:

https://www.renewableenergyhub.co.uk/main/solar-thermal-information/how-much-does-a-so lar-thermal-systemcost/\#: :text=What $\% 20$ is $\% 20$ the $\% 20 \operatorname{cost} \% 20$ of,pipes $\% 2 \mathrm{C} \% 20$ hot $\% 20 \mathrm{wa}$ ter\%20tank)

Energy Saving Trust. (2008). At home with water. [Online] Available:

https://energysavingtrust.org.uk/sites/default/files/reports/AtHomewithWater\%287\%29.pdf

Families and Households in the UK. (2015). Trends in living arrangements including families (with and without dependent children), people living alone and people in shared accommodation, broken down by size and type of household. Office of National Statistic. [Online] Available: https://www.ons.gov.uk/peoplepopulationandcommunity/birthsdeathsand marriages/families/bulletins/familiesandhouseholds/2015-11-05

Hacatoglu, K., Dincer, I., \& Rosen, M. A. (2016). Sustainability Assessment of a WindHydrogen Energy System: Assessment Using a Novel Index and Comparison to a Conventional Gas-Fired System. International Journal of Hydrogen Energy, 41(19), 
8376-8385. https://doi.org/10.1016/j.ijhydene.2016.01.135

Hobbi A., \& Siddiqui, K. (2009). Optimal Design of a Forced Circulation Solar Water Heating System for a Residential Unit in Cold Climate Using TRNSYS. Solar Energy, 83, 700-714. https://doi.org/10.1016/j.solener.2008.10.018

Jenkins, G. J., Murphy, J. M., Sexton, D. M., Lowe, J. A., Jones, P., \& Kilsby, C. G. (2010). UK Climate Projections: Briefing report. [Online] Available:

http://cedadocs.ceda.ac.uk/1321/

Koke, J., Kuhr, M., \& Clement, U. (2018). Automated Optimization of Solar-Thermal Systems Using Software in a Loop. American Journal of Energy Engineering, 5, 50-56. https://doi.org/10.11648/j.ajee.20170506.11

Krajacic, G., Vujanovic, M., Duic, N., Kilkis, S., Rosen, M. A., \& Al-Nimr, M. A. (2018). Integrated Approach for Sustainable Development of Energy, Water and Environment Systems. Energy Conversion and Management, 159, 398-412.

https://doi.org/10.1016/j.enconman.2017.12.016

Kulkarni, N., Shireesh, B., \& Kedare. S. (2008). Determination of Design Space and Optimization of Solar Water Heating Systems. Science Direct, Solar Energy, 81(2007), 958-968. https://doi.org/10.1016/j.solener.2006.12.003

Magee, L., James, P., \& Scerri, A. (2012). Measuring Social Sustainability: A Community-Centred Approach. Applied Research in the Quality of Life, 7(3), 239-61.

https://doi.org/10.1007/s11482-012-9166-x

Maria, J. (2015). Solar collectors' performance: A case study of a solar thermal heating system in a passive house dwelling. Maters thesis. Norwegian University of Science and Technology.

Moir, S., \& Carter, K. (2012) Diagrammatic representations of sustainability - A review and synthesis. In S. D. Smith (Ed.), Proceedings 28th Annual ARCOM conference. Edinburgh, UK. Association of Researchers in Construction Management. pp. 1479-1489.

Morse, S., \& Fraser, E. D. G., (2005). Making "dirty" nations look clean? The nation state and the problem of selecting weighting indices as tools for measuring progress towards sustainability. Geoforum, 36, 625-640. https://doi.org/10.1016/j.geoforum.2004.10.005

Oye, T. K. (2018). Climate Neutral Urban District in Europe. (Thesis).

Oye, T. K., Gupta, N., Goh, K., \& Oye, T. T. (2020a). A Smart and Sustainable Concept for Achieving a Highly Efficient Residential Bathroom: A Literature Review. International Journal of Innovative Science and Research Technology, 5(3).

Oye, T. K., Gupta, N., Goh, K., \& Oye, T. T. (2020b). Design of a Smart and Intelligent Energy Efficient Controller for a Bathroom System. 9th International Conference on Renewable Energy Research and Application (ICRERA), Glasgow, UK. pp. 170-174. https://doi.org/10.1109/ICRERA49962.2020.9242819 


\section{Macrothink}

Environmental Management and Sustainable Development

ISSN 2164-7682 2021, Vol. 10, No. 3

Parker J. M., \& Wilby R. L. (2014). Quantifying Household Water Demand: A Review of Theory and Practice in the UK. Water Resour Manag, 27, 981-1011.

https://doi.org/10.1007/s11269-012-0190-2

Partridge, E. (2005). 'Social sustainability': a useful theoretical framework? Paper presented at the Australasian Political Science Association Annual Conference 2005. Dunedin, New Zealand.

Polysun program. (2020). Vela Solaris Polysun Designer Version. Design of reliable and holistic energy systems. For Buildings and districts with a future. [Online] Available: https://www.velasolaris.com/?lang=en

Water UK. (2016). Water resources long term planning framework (2015-2065). [Online] Available: https://www.water.org.uk/wp-content/uploads/2018/11/WaterUK-WRLTPF_Final -Report_FINAL-PUBLISHED-min.pdf

Woodcraft, S., Bacon, N., Caistor-Arendar, L., \& Hackett, T. (2012). Design for Social Sustainability, Social Life, London.

\section{Copyright Disclaimer}

Copyright for this article is retained by the author(s), with first publication rights granted to the journal.

This is an open-access article distributed under the terms and conditions of the Creative Commons Attribution license (http://creativecommons.org/licenses/by/4.0/). 